\title{
Trabalho e Renda em Assentamentos de Juara-MT: Estudo de Caso no Assentamento P.A. - Vale do Arinos - Linha 05
}

\section{Work and Income in Juara-MT Settlements: Case Study at P.A. - Arinos Valley - Line 05 Settlement}

\author{
Gessica Danielle Batista ${ }^{\mathrm{a}}$; Alexandre Nascimento*b; Joana D’Arc da Silva Schmidt ${ }^{\mathrm{b}}$; José Francisco dos Reis Neto ${ }^{\mathrm{c}}$; Luiz \\ Antônio de Campos ${ }^{\mathrm{b}}$; Vanderleia Salete Mantovani ${ }^{\mathrm{b}}$ \\ ${ }^{\text {a} U n i v e r s i d a d e ~ d o ~ E s t a d o ~ d e ~ M a t o ~ G r o s s o, ~ U N E M A T . ~ M T, ~ B r a s i l . ~}$

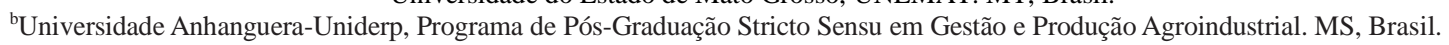 \\ 'Universidade Anhanguera-Uniderp. MS, Brasil. \\ E-mail: alexandre.nascimento@unemat.br
}

\begin{abstract}
Resumo
O trabalho que é desenvolvido pelos produtores rurais é a fonte que gera sua renda para que possam dar continuidade em suas atividades produtivas, tanto de subsistência como de comercialização, sendo assim, a administração das atividades rurais demanda de conhecimento por parte dos produtores rurais para que possam desenvolver as ferramentas de gestão e de controle dos processos que ocorrem na propriedade rural. Entretanto, o problema da pesquisa envolve: qual a renda gerada pelas atividades produtivas dos produtores rurais do Assentamento P.A. - Vale do Arinos, Linha 05 nos processos produtivos no Município de Juara - MT? Dessa forma, os objetivos específicos foram: caracterizar o espaço geossocial do Assentamento, averiguar a produção de subsistência e de comercialização, e identificar os mecanismos de gestão e de controle das atividades produtivas. A metodologia é qualitativa, sendo utilizado questionário, que foi dividido em duas etapas. A primeira apresenta a questão da análise do perfil socioeconômico do Assentamento e a segunda etapa apresenta a análise do conhecimento e utilização de ferramentas contábeis, tendo sido o questionário aplicado para 24 produtores do Assentamento. Os resultados revelados neste estudo apontam que $66,66 \%$ dos produtores rurais têm renda bruta anual entre um a cinco salários mínimos, sendo sua atividade principal a criação de gado de corte e atividade secundária, o gado leiteiro e a produção de subsistência.
\end{abstract}

Palavras-chave: Agricultura Familiar. Propriedades rurais. Renda. Trabalho.

\begin{abstract}
The work developed by rural producers is their income source to maintain their subsistence and commercial agriculture activities. Therefore, the rural administration demands knowledge from rural producers so they can develop management tools and management processes that occur in the property. However, the study problem is defined by the question: what is the income generated by agricultural activities of the rural farmers from Vale dos Arinos settlement, Line 05 in the operations in Juara, MT? The specific objectives were: characterize the geosocial space settlement, identify the mechanisms for agricultural activities management. The methodology was qualitative and a survey divided in two stages was applied in 24 producers from the settlement. The first stage presented the analysis of the settlement's socioeconomic profile while the second established the analysis of accounting knowledge and use of financial tools. The study findings show that 66.66\% of the farmers have annual gross income between one and five minimum wages, and their main activity consists of raising beef cattle while the secondary activity is raising dairy cattle and subsistence agricultural production.
\end{abstract}

Keywords: Family farming. Rural properties. Income. Work.

\section{Introdução}

Segundo o estudo de Francio (2016), a agricultura familiar é compreendida pela sua variedade de formas para fazer o cultivo da terra, em que a mão de obra é exclusivamente do núcleo familiar. É nesse contexto que se identifica que a agricultura familiar tem seus amplos significados, e cada grupo de família compõe sua forma cultural e moral; isso varia de acordo com o relacionamento em que cada grupo está inserido no seu espaço de convivência, e, assim, se transformam de acordo com seus relacionamentos.

Em contrapartida, Souza Filho e Batalha (2009) destacam que a agricultura familiar ainda é um setor atrasado, observando em questões econômicas, tecnológicas e sociais, nos quais se volta somente para a produção de alimentos básicos, sendo uma produção de subsistência.

Assim, na agricultura familiar brasileira têm sido incluídas famílias que exploram propriedade de pequeno porte e vivem em condições de extrema pobreza, como também tem produtores inseridos no mais moderno agronegócio, que geram recursos financeiros muito superiores àquela propriedade definida na linha da pobreza (SOUZA FILHO, BATALHA, 2009).

Silva et al. (2008) dispõem que o trabalho que é desenvolvido em propriedade rural pelos produtores faz com que esta gere a renda para que esses produtores possam dar continuidade em suas atividades no campo. Heleno (2009) descreve que a administração rural é uma ferramenta que veio para ajudar os produtores para que possam ampliar o desenvolvimento de suas atividades no campo a obterem mais renda no ramo da atividade desenvolvida. Para que isso aconteça, é necessário que o produtor rural obtenha conhecimento das ferramentas que auxiliam nesse processo produtivo. 
Tramontin, Piasentini e Silva (2008) destacam que quando o agricultor obtém o conhecimento e aplica essas ferramentas de gestão em sua propriedade, a propriedade se torna comercial e faz com que deixe de ser uma atividade de subsistência.

Um fator importante a ser enfrentado por esses produtores, como apontam Silva, Rech e Rech (2010), é o clima, que na maioria das vezes é imprevisível. O produtor deve tomar atitudes administrativas para se precaver de situações que possam afetar a produtividade e a lucratividade da propriedade rural.

Assim, o grande desafio do produtor familiar é desenvolver seu trabalho, complementando essa atividade com a implantação de ferramentas que possam reduzir os custos de produção para assim agregar mais valor ao produto, sempre com o controle de seus inputs e outputs para um melhor gerenciamento da produção no ramo de atividade em que a propriedade está inserida, obtendo então bons resultados, como o aumento de sua renda.

Dessa forma, o objetivo do presente trabalho foi identificar e diagnosticar a rotina de trabalho e renda nas pequenas propriedades rurais do assentamento P.A. - Vale do Arinos, Linha 05.

\section{Material e Métodos}

Esta pesquisa se configura em um estudo de caso exploratório-descritivo. Esta metodologia possibilita avaliar quais as ferramentas de controle são utilizadas para identificar os custos diretos e indiretos da propriedade rural e suas ferramentas de controle e necessidades para auxiliar em uma gestão eficiente para uma maior obtenção de renda.

A pesquisa se efetivou por meio de duas estratégias metodológicas: $i$ ) observação do participante in loco a fim de caracterizar os processos produtivos e de gerenciamentos e ii) aplicação de um questionário a fim de mensurar os dados socioeconômicos e a geração de produção, assim como os processos de gestão das propriedades pesquisadas.

O assentamento P.A Vale do Arinos Linha 05 está localizado na MT 338, cerca de $150 \mathrm{~km}$ do município de Juara-MT. A área tem sua importância econômica na atividade de criação de gado de corte e leiteiro. Participaram da pesquisa 24 assentados da área. Os assentados responderam anonimamente a um questionário elaborado pelos autores com 25 questões fechadas e 03 abertas, tendo como período de aplicação os dias 01 e 02/09/2018 e 15 e 16/09/2018 no intuito de aprofundar o diagnóstico e obter dados qualitativos e subjetivos, dificilmente identificados apenas pela aplicação do instrumento quantitativo.

\section{Resultados e análises}

Participaram da pesquisa $80 \%(n=24)$ dos 29 assentados que vivem e trabalham na área do assentamento P.A Vale do Arinos Linha 05. Todos os participantes são homens
(100\%), 54\% são casados e com baixo grau de escolaridade (com Ensino Fundamental incompleto 62,5\% e com Ensino Fundamental 25\%). A idade média dos assentados foi de 48 anos.

\subsection{Análise do perfil socioeconômico dos produtores rurais}

Para análise do perfil socioeconômico dos produtores rurais, sete perguntas foram respondidas. A primeira pergunta: "Qual o tipo de mão de obra é usado na propriedade?" mostrou que $79 \%$ da mão de obra é totalmente familiar, enquanto apenas $4 \%$ é parcialmente contratada (Quadro 1).

Quadro 1 - Tipo de mão de obra usada no assentamento P.A Vale do Arinos Linha 05

\begin{tabular}{|l|c|c|}
\hline \multicolumn{1}{|c|}{ Alternativa } & $\mathbf{N}^{\mathbf{0}}$ & $\mathbf{\%}$ \\
\hline Totalmente Familiar & 19 & 79,16 \\
\hline Parceria & 0 & 0 \\
\hline Terceirizada e Familiar & 04 & 16,66 \\
\hline Parcialmente Contratada & 01 & 4,16 \\
\hline Totalmente Contratada & 0 & 0 \\
\hline
\end{tabular}

Fonte: Dados da pesquisa.

Gabori Junior (2013, p.2) expõe que "a agricultura familiar no Brasil, hoje, produz a maior parte dos alimentos que abastecem a mesa dos Brasileiros". Entretanto, essa produção desenvolvida pela agricultura familiar está inteiramente ligada com a alimentação de todo o Planeta. Assim, a agricultura familiar, como ressalta o autor, está completamente introduzida nas mesas das pessoas como fonte de alimentação, se tornando primordial para sobrevivência de muitas famílias do Brasil e do mundo.

O questionário aplicado no Assentamento P.A. - Vale do Arinos, Linha 05, corrobora com o que Gabori Junior (2013) afirma, pois a mão de obra nessas pequenas propriedades rurais é de maioria familiar, podendo observar de acordo com os dados apontados, a importância que essas famílias que moram nessas pequenas propriedades rurais têm para

o desenvolvimento de alimentos para nutrição de muitas famílias da região do Mato Grosso, assim como para o Brasil.

A segunda questão: "Quais as principais atividades econômicas desenvolvidas na propriedade?" mostrou que $91,66 \%$ dos assentados pratica a pecuária de corte (Quadro 2).

Quadro 2 - Atividades econômicas desenvolvidas no assentamento P.A Vale do Arinos Linha 05.

\begin{tabular}{|l|l|c|}
\hline \multicolumn{1}{|c|}{ Alternativa } & $\mathbf{N}^{\mathbf{0}}$ & $\mathbf{\%}$ \\
\hline Pecuária de Corte & 22 & 91,66 \\
\hline Pecuária Leiteira & 09 & 37,50 \\
\hline Agricultura & 01 & 4,16 \\
\hline Nenhum & 01 & 4,16 \\
\hline
\end{tabular}

Fonte: Dados da pesquisa.

Com os dados da pesquisa se pode destacar que no assentamento predomina a pecuária de corte, como também o manejo do gado leiteiro, se tornando uma segunda fonte de renda, totalizando $37,50 \%$ da atividade desenvolvida por esses pequenos produtores rurais, como destaca o Quadro 2. 
Consequentemente, o que mantém e gera lucratividade para manter suas propriedades rurais é a criação de gado de corte, que é comercializado na região (Quadro 2).

Ferro e Vechi (2014, p.11) comentam que na região de Mato Grosso se estimaque "atualmente são produzidos no Estado aproximadamente 2,5 milhões de leite/dia na época das águas e 1,7 milhões de leite/dia na época da seca. Estimase que no Estado existem cerca de 30.000 produtores de leite, dos quais $90 \%$ são agricultores familiares [...]". Este dado mostra que a agricultura familiar tem grande importância e relevância tanto para a pecuária de corte, como leiteira no Brasil.

A terceira questão: "Qual produto é produzido na agricultura familiar para subsistência?" mostrou que entre os produtos de origem vegetal, a alface é produzida por 95,83\% dos agricultores, sendo o mesmo índice da produção animal de gado (Quadro 3).

Quadro 3 - Produção desenvolvida para subsistência no assentamento.

\begin{tabular}{|l|c|c|}
\hline \multicolumn{1}{|c|}{ Produtos } & $\mathbf{N}^{\mathbf{o}}$ & $\mathbf{\%}$ \\
\hline Alface & 23 & 95,83 \\
\hline Gado & 23 & 95,83 \\
\hline Frango & 22 & 91,66 \\
\hline Mandioca & 20 & 83,33 \\
\hline Pepino & 19 & 79,16 \\
\hline Leite & 18 & 75,00 \\
\hline Rúcula & 17 & 70,83 \\
\hline Porco & 17 & 70,83 \\
\hline Couve & 15 & 62,50 \\
\hline Abóbora & 13 & 54,16 \\
\hline Queijo & 07 & 29,16 \\
\hline Feijão & 06 & 25,00 \\
\hline Requeijão & 02 & 8,33 \\
\hline Carneiro & 02 & 8,33 \\
\hline Abacaxi & 02 & 8,33 \\
\hline Milho & 02 & 8,33 \\
\hline Outros = Doce de Leite & 01 & 4,16 \\
\hline Caju & 01 & 4,16 \\
\hline Melão & 01 & 4,16 \\
\hline Melancia & 01 & 4,16 \\
\hline Peixe & 01 & 4,16 \\
\hline Café & 01 & 4,16 \\
\hline Cupuaçu & 01 & 4,16 \\
\hline Ovo & 01 & 4,16 \\
\hline Batata Doce & 01 & 4,16 \\
\hline Repolho & & 0 \\
\hline
\end{tabular}

Fonte: Dados da pesquisa.

No assentamento, os produtores rurais além de cuidarem do gado, que é a atividade de geração de renda mais desenvolvida e cuidar dos afazeres da propriedade, ainda produzem alimentos para seu consumo diário. Hagemann (2018) apresenta a produção para autoconsumo como ferramenta utilizada pelas unidades familiares com o objetivo de consumir seu alimento. Esse alimento segue direto da unidade de produção para a mesa da família, sem intermediações, acarretando acréscimo no valor econômico.

Entretanto, os alimentos produzidos nas propriedades rurais pesquisadas para autoconsumo, de acordo com o Quadro 3 , é a mandioca $(83,33 \%)$, alface $(95,83 \%)$, queijo $(29,16 \%)$, rúcula $(70,83)$, abóbora $(54,16 \%)$, pepino $(79,16 \%)$, couve $(62,50 \%)$, feijão $(25,00 \%)$, frango $(91,66 \%)$, porco $(70,83 \%)$, leite $(75,00 \%)$, entretanto, esses alimentos são produzidos no decorrer de todo o ano, no qual os produtores buscam nos supermercados da região somente o necessário para dar base para sua vida familiar. Observa-se também a variedade de produtos produzidos para consumo, e a riqueza de alimentos que trazem a segurança alimentar desses produtores.

A quarta questão com referência a "Quantos alqueires são utilizados para a produção do ramo de atividade que a propriedade desenvolve?" mostrou que 79,16\% dos entrevistados utilizam como área produtiva mais de 30 alqueires (Quadro 4).

Quadro 4 - Quantidade de Alqueires para Produção.

\begin{tabular}{|c|c|c|}
\hline Alternativa & $\mathbf{N}^{\mathbf{0}}$ & \% \\
\hline 01 a 06 & 01 & 4,16 \\
\hline 07 a 12 & 02 & 8,33 \\
\hline 13 a 18 & 0 & 0 \\
\hline 19 a 24 & 01 & 4,16 \\
\hline 25 a 30 & 01 & 4,16 \\
\hline 31 a 36 & 08 & 33,33 \\
\hline 37 a 42 & 11 & 45,83 \\
\hline
\end{tabular}

Fonte: Dados da pesquisa.

Assim, para desenvolvimento da pecuária no Assentamento P.A. - Vale do Arinos, Linha 05, os agricultores familiares têm, na sua maioria, uma pequena propriedade com aproximadamente 42 alqueires $(45,83 \%)$, porém os dados apontados mostram que outros produtores utilizam uma extensão territorial menor de 31 a 36 alqueires, totalizando $33,33 \%$ das propriedades pesquisadas, ou seja, utiliza-se toda a propriedade para formação de pastos para dar sustento ao gado que é comercializado para obtenção de renda.

A quinta questão sobre: "Como planeja a atividade econômica de sua propriedade?" evidencia que 95,83\% dos pesquisados desenvolvem um plano de trabalho apenas utilizando seus conhecimentos empíricos.

Quadro 5- Planejamento da Atividade Econômica a ser desenvolvida na propriedade

\begin{tabular}{|l|c|c|}
\hline \multicolumn{1}{|c|}{ Alternativa } & $\mathbf{N}^{\mathbf{o}}$ & $\mathbf{\%}$ \\
\hline $\begin{array}{l}\text { Desenvolve um plano de trabalho tendo } \\
\text { como base suas experiências }\end{array}$ & 23 & 95,83 \\
\hline $\begin{array}{l}\text { Desenvolve um plano de trabalho com } \\
\text { objetivos, metas e controles definidos }\end{array}$ & 0 & 0 \\
\hline Desenvolve pesquisa de mercado & 0 & 0 \\
\hline Outro (Economizando) & 01 & 4,16 \\
\hline
\end{tabular}

Fonte: Dados da pesquisa.

É importante que os produtores rurais façam um planejamento antes de qualquer atitude para que não haja prejuízos futuros. No entanto, no assentamento pesquisado, 
os produtores desenvolvem seu plano de trabalho de acordo com suas experiências de vida, ou seja, 95,83\% desses produtores não têm planejamento, como também não fazem uma pesquisa de mercado para atingir os objetivos esperados e proporcionalmente atender à demanda de mercado.

A sexta questão sobre: "Qual a renda bruta anual proveniente das atividades econômicas desenvolvidas na propriedade?" mostrou que $66,66 \%$ dos assentados conseguem uma renda bruta anual entre 1 a 5 salários mínimos (Quadro $6)$.

Quadro 6 - Renda Bruta Anual resultante da atividade econômica da propriedade

\begin{tabular}{|c|c|c|}
\hline Alternativa/ salário mínimo & $\mathbf{N}^{\mathbf{o}}$ & \% \\
\hline Menos 01 & 0 & 0 \\
\hline 01 a 05 & 16 & 66,66 \\
\hline 05 a 10 & 02 & 8,33 \\
\hline 11 a 15 & 02 & 8,33 \\
\hline 16 a 20 & 01 & 4,16 \\
\hline Acima 20 & 03 & 12,50 \\
\hline
\end{tabular}

Fonte: Dados da pesquisa.

A baixa remuneração, possivelmente, é resultado do desenvolvimento desta atividade econômica sem utilização de planejamento, de controle e de tecnologias, fazendo com que a maioria dos produtores do assentamento pesquisado não ultrapasse uma margem de renda bruta anual de 01 a 05 salários.

Na sétima questão em como "É feito o controle de custo para cada atividade? Como é feito o controle de custo para cada atividade?" mostrou que não existe controle frequente por parte de nenhum dos assentados e entre os que fazem o controle, 66,66\% dos assentados só o faz de cabeça (Quadro 7).

Quadro 7 - Controle de Custo por atividade desenvolvida

\begin{tabular}{|l|c|c|}
\hline \multicolumn{1}{|c|}{ Alternativa } & $\mathbf{N}^{\mathbf{0}}$ & \% \\
\hline Frequentemente & 0 & 0 \\
\hline Às vezes & 13 & 54,16 \\
\hline Poucas vezes & 02 & 8,33 \\
\hline Raramente & 09 & 37,50 \\
\hline $\begin{array}{l}\text { Tudo é feito na memória (de } \\
\text { cabeça) }\end{array}$ & 16 & 66,66 \\
\hline Anotação em caderno & 8 & 33,33 \\
\hline Planilha em papel & 0 & 0 \\
\hline Planilha eletrônica & 0 & 0 \\
\hline Algum sistema de informação & 0 & 0 \\
\hline
\end{tabular}

Fonte: Dados da pesquisa.

Grande parte dos agricultores familiares não faz o planejamento de sua propriedade. De acordo com o Senar (2015), os produtores no geral não têm o hábito de anotar o que acontece em sua propriedade como seus planos, contas a receber e a pagar, entre outras modalidades que fazem parte desse contexto de planejamento, mas de certa forma algumas modalidades que são utilizadas por esses agricultores se observam na prática. $\mathrm{O}$ agricultor talvez utilize da ferramenta de planejamento, mas muitas vezes não sabe que está utilizando ou não tem conhecimento que a desenvolve na sua propriedade rural.

Observa-se que o controle de custo é superficial, ou seja, $54,16 \%$ dos produtores às vezes fazem o controle de custos de apenas contas a pagar e receber, de acordo com anotações em cadernos ou idealizações de datas de venda e pagamento na mente do produtor. Desses produtores, $66,66 \%$ faz o controle de cabeça, assim dificultando que outra pessoa da família entenda o negócio ou possa suceder sobre a área.

\subsection{Análise de utilização de ferramentas gerenciais}

Em uma segunda parte do questionário, nove perguntas foram feitas para evidenciar o conhecimento e a utilização efetuados pelos assentados com relação à gestão e ao controle da propriedade.

Neste tópico foram apresentadas as questões que têm a intenção de avaliar como é feito o controle financeiro das propriedades rurais e o conhecimento e utilização de ferramentas gerenciais pelos próprios produtores do assentamento pesquisado.

Na questão: “Quem administra/gerencia a propriedade?" evidenciou que em $100 \%$ das propriedades pesquisadas é o produtor quem faz o papel de administrar os processos que ocorrem dentro da propriedade, desde o cuidado com o gado até a venda do mesmo para obtenção de renda (Quadro 8).

Quadro 8 - Administração/Gerenciamento da Propriedade Rural

\begin{tabular}{|l|c|c|}
\hline \multicolumn{1}{|c|}{ Alternativa } & $\mathbf{N}^{\mathbf{0}}$ & \% \\
\hline Somente eu & & \\
\hline Eu e minha família & 24 & 100 \\
\hline Tenho auxílio especializado & 0 & 0 \\
\hline
\end{tabular}

Fonte: Dados da pesquisa.

O gerenciamento da propriedade rural é efetuado pelos proprietários dos lotes, que conforme ficou evidenciado na pesquisa, não possuem nenhuma qualificação acadêmica para tal atividade, o que dificulta o entendimento das ações necessárias para o desenvolvimento das atividades.

Na questão: "Você acha que seu conhecimento sobre gestão para controlar sua propriedade é:" evidenciou que em os assentados consideram que seu conhecimento quanto à gestão é insatisfatório (Quadro 9).

Quadro 9 - Conhecimento sobre gestão para controlar a propriedade rural.

\begin{tabular}{|l|c|c|}
\hline \multicolumn{1}{|c|}{ Alternativa } & $\mathbf{N}^{\mathbf{0}}$ & $\mathbf{\%}$ \\
\hline Totalmente satisfatório & 0 & 0 \\
\hline Parcialmente satisfatório & 0 & 0 \\
\hline Neutro & 0 & 0 \\
\hline Parcialmente insatisfatório & 03 & 12,50 \\
\hline Totalmente insatisfatório & 21 & 87,50 \\
\hline
\end{tabular}

Fonte: Dados da pesquisa.

Para os produtores, o conhecimento sobre gestão é um fator que afeta significativamente para o aumento da renda 
dessas propriedades. Tramontin, Piasentini e Silva (2008) dizem que para a agricultura familiar obter uma lucratividade, para que possa fazer um desenvolvimento da terra, é necessário que o produtor tenha um modelo de gestão atrelado com as particularidades do negócio, assim passando a ser uma atividade competitiva no mercado e deixando de ser somente uma atividade de subsistência.

Sendo assim, $87,50 \%$ desses produtores estão totalmente insatisfeitos com seu modo de gestão ou a forma como gerenciam a propriedade rural, pois esses produtores na maior parte das vezes não desenvolvem nenhum tipo de gestão sobre a propriedade.

Na questão: "Você separa seus gastos particulares, como comida, roupas, produtos de limpeza, dos gastos da propriedade (ração para animais, adubos, sementes)?” 100\% respondem que não há separação das contas familiares com as contas da propriedade.

Tramontin, Piasentini e Silva (2008) destacam que o controle financeiro e orçamento de caixa têm grande importância para que o produtor tome conhecimento de seus gastos, assim possibilita ao produtor saber qual o retorno que está tendo com a atividade desenvolvida em cima da propriedade com o custo da produção.

Na questão: "Como são os controles da propriedade?" fica evidenciado que não há um controle sistematizado da propriedade e sim um controle realizado apenas na cabeça da maioria dos proprietários (Quadro 10).

Quadro 10 - Controle da Propriedade do assentamento

\begin{tabular}{|l|c|c|}
\hline \multicolumn{1}{|c|}{ Alternativa } & $\mathbf{N}^{\mathbf{0}}$ & \% \\
\hline Não faço & 0 & 0 \\
\hline Sei tudo de cabeça & 16 & 66,66 \\
\hline $\begin{array}{l}\text { Tenho tudo anotado em um } \\
\text { caderno }\end{array}$ & 8 & 33,33 \\
\hline Uso planilhas no computador & 0 & 0 \\
\hline $\begin{array}{l}\text { Tenho um sistema (programa) } \\
\text { que controla tudo }\end{array}$ & 0 & 0 \\
\hline
\end{tabular}

Fonte: Dados da pesquisa.

Com relação ao controle desenvolvido nas propriedades do assentamento, o Quadro 10 mostrou que 66,66\% dos produtores apontam que sabem tudo de cabeça, ou seja, não fazem qualquer tipo de anotação. Senar (2015) destaca que a maioria dos produtores não faz qualquer tipo de anotação para saber o que acontece em sua propriedade rural, como por exemplo, seus planos, contas a receber e pagar, entre outras atividades que são desenvolvidas no seu dia a dia. Entretanto, os $33,33 \%$ dos produtores que fazem anotações em caderno, como destaca o Quadro 10, se trata de um controle superficial, em que se anota somente o controle de custo sobre contas a pagar e receber.

Na questão: "Você sabe qual o lucro da propriedade, controlando quanto entra e quanto sai de dinheiro?" $100 \%$ não possui conhecimento dos resultados obtidos pela produção. Os produtores do Assentamento não sabem qual o lucro que se tem com suas entradas e saídas de dinheiro adquirido com a atividade que desenvolvem na propriedade rural. Sendo assim, Tramontin, Piasentini e Silva (2008) apontam que o produtor rural necessita ter um controle de caixa para assim possibilitar ter uma visão clara de suas entradas e saídas e saber qual a renda que está tendo com a atividade desenvolvida na propriedade, possibilitando ao produtor fazer investimento para o aumento de sua lucratividade.

Na questão: "Você faz controle do valor das perdas, como por exemplo, morte ou doença de animais, ou perda de plantação por pestes ou tempestades?". Percebeu-se que não existe controle de perdas em $100 \%$. Os produtores não fazem qualquer tipo de controle sobre a perda que se tem na propriedade. Silva, Rech e Rech (2010) afirmam que o produtor para ter boa administração de seu negócio precisa conhecer todo o processo que envolve sua produção, para só depois chegar ao produto para comercialização. Os autores ressaltam que na área rural existem várias peculiaridades que afetam negativamente a produção, então o produtor rural deve desenvolver ações administrativas para diminuir os impactos causados por esses fenômenos.

Na questão: "Você planeja quanto precisa produzir para chegar a determinado lucro?" Também foi verificado que não há planejamento para produção. Silva, Rech e Rech (2010) apontam que o produtor necessita ter planejamento de tudo que ocorre dentro da propriedade para que não haja perdas, nem prejuízos, ou seja, com planejamento o produtor pode tomar decisões fundamentais na hora certa. Essa questão demostrou que $100 \%$ dos produtores não fazem qualquer tipo de planejamento para obter determinado lucro, ou seja, não sabem se estão tendo lucro ou prejuízo com a atividade que desenvolvem.

A questão: "Você reinveste seu lucro na propriedade, comprando máquinas e/ou animais ou melhorando o processo produtivo?" mostrou que nenhum assentado reinveste o lucro da produção para melhorias. Pode-se visualizar que $100 \%$ dos produtores não fazem investimentos na propriedade com os lucros obtidos. Os produtores só fazem investimento quando sobra dinheiro e, geralmente, este investimento é como, por exemplo, a compra para reposição de gado, horas de serviço com trator para gradear a pastagem, compra de capim para reforma de pastagem, arame para reforma de cercas, entre outros investimentos que fazem com que agregue valor à propriedade, ajudando no desenvolvimento da atividade exercida pelo produtor.

Na questão: "Como você considera o controle da sua propriedade? E se o controle foi satisfatório?" os proprietários se consideram insatisfeitos com o controle que têm, mas têm uma ideia do quanto sobra por mês (Quadro 11). 
Quadro 11 - Controle financeiro da propriedade.

\begin{tabular}{|l|c|c|}
\hline \multicolumn{1}{|c|}{ Alternativa } & $\mathbf{N}^{\mathbf{0}}$ & $\mathbf{\%}$ \\
\hline Totalmente insatisfatório & 24 & 100 \\
\hline Parcialmente insatisfatório & 0 & 0 \\
\hline Neutro & 0 & 0 \\
\hline Parcialmente satisfatório & 0 & 0 \\
\hline Totalmente satisfatório & 0 & 0 \\
\hline \multicolumn{1}{|c|}{ Alternativa } & $\mathbf{N}^{\mathbf{0}}$ & $\mathbf{\%}$ \\
\hline $\begin{array}{l}\text { Não sei dizer quanto sobra } \\
\text { por mês }\end{array}$ & 0 & 0 \\
\hline $\begin{array}{l}\text { Me dá uma ideia de quanto } \\
\text { sobra }\end{array}$ & 24 & 100 \\
\hline $\begin{array}{l}\text { Sei quanto sobra na } \\
\text { propriedade, mas não por } \\
\text { atividade }\end{array}$ & 0 & 0 \\
\hline $\begin{array}{l}\text { Sei exatamente quanto sobra } \\
\text { na propriedade em cada } \\
\text { atividade }\end{array}$ & 0 & 0 \\
\hline
\end{tabular}

Fonte: Dados da pesquisa.

Silva e Buss (2011) afirmam que a administração é de suma importância para a propriedade rural, pois é a partir dessa ferramenta que o produtor deixa de ser uma produção de subsistência e seu negócio passa a ter resultados econômicos satisfatórios. Sendo assim, o Quadro 11 destaca que 100\% dos produtores pesquisados estão totalmente insatisfeitos com o controle que exercem em suas atividades, entretanto, a mesma tabela mostra que $100 \%$ desses produtores argumentam que têm uma noção de quanto sobra da atividade desenvolvida. Ainda pontuam que se sentem desmotivados a desenvolver outras atividades em sua área em função da falta de assistência pelos órgãos responsáveis pelo assentamento.

\section{Conclusão}

Sabe-se que os assentados necessitam contemplar suas atividades produtivas, bem como desenvolver sua renda sobre a propriedade rural. Entretanto, esses produtores, por terem um conhecimento somente da prática, empírico, não desenvolvem resultados positivos que possam fazem com que esses produtores tenham vantagens competitivas no mercado, não contribuindo para se obter uma melhor renda da atividade desenvolvida.
Além disso, o resultado da pesquisa aponta que os produtores utilizam apenas a gestão do dia a dia, com apontamentos em cadernos ou na "cabeça". Os produtores rurais do assentamento P.A Vale do Arinos Linha 05 não desenvolvem qualquer tipo de planejamento para saber o quanto precisam produzir para chegar a um determinado lucro e, automaticamente, suas decisões são baseadas de acordo com suas experiências de vida.

Esta ausência de conhecimento ocasiona a não execução de uma gestão administrativa ou financeira, que abranja a parte de planejamento e controle sobre a propriedade rural, e seus processos são desenvolvidos de forma superficial.

\section{Referências}

FERRO, A.S.; VECHI, J.B. Contextualização da agricultura familiar em Mato Grosso. Oficina de Concertação Estadual de Mato Grosso. Embrapa. Sinop - MT. 2014.

FRANCIO, N. Agricultura familiar: trabalho, renda e associativismo. Curitiba: Appris, 2016.

GABORI JUNIOR, A. A importância da produção na agricultura familiar para a segurança alimentar. 2013. $2^{a}$. Jornada Questão Agraria Desenvolvimento - UFPR - 06 e 07 de novembro de 2013. Paraná. 2013.

HELENO, G. Administração rural: as oportunidades do Brasil rural. $R B A$, v.19. n.70, p.22 2009.

SENAR, Serviço Nacional de Aprendizagem Rural. Curso Técnico em Agronegócio: Administração Rural. Brasília. 2015.

SILVA, C. et al. Análise da rentabilidade de pequenas propriedades rurais. ANPAD, 2008, Rio de Janeiro. Anais... Rio de Janeiro, 2008.

SILVA, M.Z.; RECH, L.C.; RECH, G.M. Estudo sobre as práticas de gestão utilizadas no gerenciamento das pequenas propriedades rurais de Guaramirim. Rev. Ciênc. Soc. Perspectiva, v.9, n.17, 2010.

SILVA, P.; BUSS, R.N.A Administração na pequena propriedade rural. Rev. São Luis Orione, v.1, n.5, p.149-173, 2011.

SOUZA FILHO, H.M.; BATALHA, M.O. Gestão integrada da agricultura familiar. São Carlos: Edufscar, 2005

TRAMONTIN, M.; PIASENTINI, E.; SILVA, M.R. Ferramentas de gestão para a tomada de decisão na propriedade rural familiar. Rev. Synergismus Scy., v.3, n.1, 2008 